\title{
Glycine betaine biosynthesis and catabolism in bacteroids of Rhizobium meliloti : effect of salt stress
}

\author{
F. FOUGÈRE and D. LE RUdULIER* \\ Laboratoire de Biologie Végétale et Microbiologie, URA CNRS 1114, Faculté des Sciences et des Techniques, Université \\ de Nice - Sophia Antipolis, Parc Valrose, 06034 Nice Cedex, France
}

(Received 18 April 1990; accepted 9 August 1990)

\begin{abstract}
In medium of low or high osmolarity, bacteroids isolated from Medicago sativa nodules induced by Rhizobium meliloti 102F34 rapidly catabolized $\left[{ }^{14} \mathrm{C}\right]$ choline. Trimethylamine was never detected and glycine betaine was the predominant product within the ethanol-soluble fraction of bacteroids subjected to salt stress $(0 \cdot 4 \mathrm{M}-\mathrm{NaCl})$. Both choline oxidase and glycine betaine aldehyde dehydrogenase activities were characterized; the apparent $K_{\mathrm{m}}$ values for choline and glycine betaine aldehyde were 2.0 and $0.4 \mathrm{mM}$, respectively. A $3 \mathrm{~h}$ incubation of the bacteroids in medium of high osmolarity, supplemented or not with choline, did not significantly modify the specific activity of the two enzymes. Similarly, salinization of the host plants for 2 weeks with $0 \cdot 15 \mathrm{M}-\mathrm{NaCl}$ had only a slight effect on both enzymic activities. Thus, the choline-glycine betaine biosynthetic pathway was not modulated by the external osmotic pressure. Glycine betaine itself was actively degraded by bacteroids suspended in low-osmolarity medium, but the demethylation process producing sarcosine and glycine was extremely slow in bacteroids subjected to salt stress. Thus, high concentration of glycine betaine can be maintained in salt-stressed bacteroids.
\end{abstract}

\section{Introduction}

Growth inhibition of Rhizobium meliloti by salt stress can be relieved by addition of various osmoprotectants to the growth medium. Among these molecules, glycine betaine and proline betaine have been shown to be the most effective (Bernard et al., 1986; Smith et al., 1988). Choline also has an osmoprotective effect as a consequence of its oxidation to glycine betaine (Le Rudulier $e t$ al., 1984; Smith et al., 1988). Furthermore, nitrogen fixation by the symbiotic association Medicago sativa- $R$. meliloti is greatly reduced by osmotic stress, and is partially restored by adding glycine betaine or proline betaine to the nutrient medium (Pocard et al., 1984). It was suggested that these compounds could be transported into the root nodules and taken up by the bacteroids. A consequence of this uptake could be a protective effect on nitrogenase biosynthesis and activity as previously shown for Klebsiella pneumoniae subjected to salt stress (Le Rudulier et al., 1982).

In order to analyse this possibility, we have recently investigated the transport of glycine betaine, proline betaine and choline by bacteroids isolated from $M$. sativa nodules (Fougère \& Le Rudulier, 1990). These three compounds are effectively transported by free bacteroids. Glycine betaine uptake is strongly stimulated by sodium salts, whereas addition of energy-yielding substrates or ATP has no effect. This transport is via an active process. In contrast, choline transport by bacteroids remains comparatively low, whatever the concentration of $\mathrm{NaCl}$. The existence of an important passive diffusion component was suggested (Fougère \& Le Rudulier, 1990).

Choline oxidation and the fate of glycine betaine are well known in different bacteria and plants. In osmotically stressed cells of Escherichia coli, choline is the precursor of glycine betaine but only cells grown in choline-containing medium display full enzymic activity (Landfald \& Strøm, 1986). In $R$. meliloti the same choline-glycine betaine pathway has been characterized but the specific activities of the two enzymes that catalyse glycine betaine production either remain constant (choline oxidase) or barely increase (glycine betaine aldehyde dehydrogenase) when cultures are osmotically stressed (Smith et al., 1988). In E. coli, glycine betaine cannot be used as a building block for cellular components (Perroud \& Le Rudulier, 1985), whereas $R$. meliloti catabolizes this compound at low osmolarity, salvaging both carbon and nitrogen (Bernard et al., 1986; Smith et al., 1988). In plants, in vivo radiotracer work (Hanson \& Hitz, 1982) has established that betaine is synthesized in leaves by a two-step oxidation of choline. In spinach, 
both steps are chloroplastic (Hanson et al., 1985), and glycine betaine aldehyde dehydrogenase is induced several-fold in response to gradual salinization of spinach plants (Weigel et al., 1986). Great resistance of glycine betaine to metabolic degradation has usually been noted in plants such as wheat (Bowman \& Rohringer, 1970), barley (Ladyman et al., 1980) and sugar beet (Hanson \& Wyse, 1982). In most cases, glycine betaine metabolism in crop species has been studied in the Gramineae (Ladyman et al., 1980; Grumet \& Hanson, 1986; MacDonnell \& Wyn Jones, 1988) or in the Chenopodiaceae (Hanson \& Rhodes, 1983; Hanson \& Wyse, 1982; Weigel et al., 1988). Very few reports have dealt with betaine metabolism in legumes (Sethi \& Carew, 1974) and nothing is known about the biosynthesis and the catabolism of glycine betaine by bacteroids.

In this work, we have examined the effect of salt stress on the fate of labelled choline and glycine betaine provided to isolated bacteroids of $R$. meliloti. We have also conducted enzymological studies of the cholineglycine betaine pathway and determined the effect of $\mathrm{NaCl}$ on choline oxidase and glycine betaine aldehyde dehydrogenase.

\section{Methods}

Organism and culture conditions. Rhizobium meliloti 102F34 was maintained and grown as described previously (Fougère \& Le Rudulier, 1990) in mannitol/salts/yeast extract medium.

Nodule production. Alfalfa plants were obtained by clonal propagation of shoot cuttings from a single Medicago sativa L. (cv. Europe) plant. They were grown aeroponically through a two-step procedure (Fougère \& Le Rudulier, 1990), and inoculated with a washed suspension of bacteria. Four-week-old nodules were harvested and used immediately for bacteroid preparation. In some cases, plants were subjected to salt stress by adding $0.15 \mathrm{M}-\mathrm{NaCl}$ to the nitrogen-free growth medium. Salinization was applied for 2 weeks before nodules were harvested.

Bacteroid isolation. Nodules ( $1-2 \mathrm{~g}$ fresh wt) were surface-sterilized with calcium hypochlorite $(0.5 \%, \mathrm{pH} 7.0)$ for $5 \mathrm{~min}$ and abundantly rinsed with sterile water. They were crushed in a glass mortar and bacteroids were isolated by differential centrifugations as previously described (Fougère \& Le Rudulier, 1990). Finally, they were resuspended in $25 \mathrm{~mm}$-potassium phosphate buffer ( $\mathrm{pH} \mathrm{7.4)}$ to a final concentration of $40 \mathrm{mg}$ dry wt $\mathrm{ml}^{-1}$.

Catabolism and fate of radioactive choline and glycine betaine. Bacteroid suspension $(0.7-0.9 \mathrm{mg}$ protein) were incubated aerobically at $25^{\circ} \mathrm{C}$, in Warburg vials, in $25 \mathrm{~mm}$-potassium phosphate buffer, pH 7.4 ( $1 \mathrm{ml}$ final volume), plus $0.4 \mathrm{M}-\mathrm{NaCl}$ if necessary, and supplemented with $\left[1,2-{ }^{14} \mathrm{C}\right]$ choline $(8 \mu \mathrm{M})$ or $\left[1,2-{ }^{14} \mathrm{C}\right]$ glycine betaine $(9 \mu \mathrm{M}) . \mathrm{CO}_{2}$ was trapped in $0 \cdot 1 \mathrm{ml} 6 \mathrm{M}-\mathrm{KOH}$. At indicated intervals, the bacteroids were rapidly collected on glass microfibre filters $(\mathrm{GF} / \mathrm{F}$, Whatman) and extracted with $70 \%(\mathrm{v} / \mathrm{v})$ ethanol as described by Bernard et al. (1986). Radioactivity of each resulting fraction $\left(\mathrm{CO}_{2}\right.$, ethanol-insoluble, ethanol-soluble) was measured by liquid scintillation using a Kontron spectrometer. The labelled compounds of the soluble fraction were separated by high-voltage paper electrophoresis ( $70 \mathrm{~min}$,
$40 \mathrm{~V} \mathrm{~cm}^{-1}$ ) on Whatman $3 \mathrm{MM}$ paper presoaked in $0.75 \mathrm{M}$-formic acid (pH 2.0). After drying at $40^{\circ} \mathrm{C}$, the electrophoregrams were sprayed with Dragendorff's reagent or ninhydrin solution. Radioactivity of ethanol-soluble compounds was determined by scintillation counting (Bernard et al., 1986).

Toluene treatment and disruption of bacteroids for enzyme assays. For routine determination of choline oxidase activity, the bacteroids were suspended in $100 \mathrm{~mm}$-potassium phosphate buffer $\mathrm{pH} 7.6$ and treated with toluene. Toluene $(0.5 \%, \mathrm{v} / \mathrm{v})$ was added to the suspension, and the mixture was shaken for $10 \mathrm{~min}$ at 250 r.p.m., $30^{\circ} \mathrm{C}$, to permeabilize the bacteroids. Choline oxidase activity was always assayed immediately after the toluene treatment. For measurement of glycine betaine aldehyde dehydrogenase activity, the bacteroids were suspended in $100 \mathrm{~mm}$-potassium phosphate buffer $\mathrm{pH} 7.6$, and disrupted by two passages through a French press at 16000 p.s.i. (110.3 MPa). The debris was removed by centrifugation at $7000 \mathrm{~g}$ for $10 \mathrm{~min}$ at $4{ }^{\circ} \mathrm{C}$. The resulting supernatant constituted the crude enzymic extract.

Choline oxidase and glycine betaine aldehyde dehydrogenase assays. Choline oxidase (EC 1.1.3.17) activity was determined by measuring production of $\left[\right.$ methyl $\left.-{ }^{14} \mathrm{C}\right]$ betainal from $\left[\right.$ methyl $\left.{ }^{-14} \mathrm{C}\right]$ choline as described by Landfald \& Strøm (1986). Incubation mixtures $(0.25 \mathrm{ml})$ contained approximately $1 \mathrm{mg}$ protein, $80 \mathrm{~mm}$-sodium bisulphite, $76 \mathrm{~mm}$-potassium phosphate $\left(\mathrm{pH} \mathrm{7.6)}\right.$ and $10 \mathrm{~mm}-\left[\right.$ methyl $\left.-{ }^{14} \mathrm{C}\right]$ choline (except where otherwise indicated). The reaction mixture was incubated aerobically with shaking (200 r.p.m.) at $30^{\circ} \mathrm{C}$, and measurement was made after $30 \mathrm{~min}$ incubation. $\left[{ }^{14} \mathrm{C}\right]$ Betainal was isolated by ion-exchange chromatography and quantified by liquid scintillation counting (Landfald \& Strøm, 1986).

Glycine betaine aldehyde dehydrogenase (EC 1.2.1.8) activity was determined by measuring NADH production from glycine betaine aldehyde and $\mathrm{NAD}^{+}$spectrophotometrically at $340 \mathrm{~nm}$. The reaction mixure $(1 \mathrm{ml})$ contained $10 \mathrm{~mm}-\mathrm{NAD}^{+}, 1 \mathrm{~mm}$-glycine betaine aldehyde (unless otherwise indicated) and approximately $0.4 \mathrm{mg}$ protein in $100 \mathrm{~mm}$-potassium phosphate buffer ( $\mathrm{pH} 7 \cdot 6$ ). Under these conditions, interfering activities in the crude extracts which oxidize NADH were not detected.

Under the conditions given, both enzyme activities were linear with time. They were expressed as nmol product formed $\mathrm{min}^{-1}$ (mg protein) $)^{-1}$.

Radioisotopes. [methyl ${ }^{14} \mathrm{C}$ Choline $\left(2.04 \mathrm{MBq}^{2} \mathrm{~mol}^{-1}\right)$ and [1,2${ }^{14} \mathrm{C}$ ]choline $\left(1.67 \mathrm{MBq} \mu \mathrm{mol}^{-1}\right)$ were purchased from Amersham and New England Nuclear, respectively. [methyl $\left.{ }^{14} \mathrm{C}\right]$ Glycine betaine and $\left[1,2-{ }^{14} \mathrm{C}\right]$ glycine betaine were prepared from the corresponding $\left[{ }^{14} \mathrm{C}\right]$ choline as described by Perroud \& Le Rudulier (1985).

Protein determinations. The protein concentrations of bacteroid suspensions or extracts were determined by the Lowry method with bovine serum albumin as the standard.

\section{Results}

\section{Choline oxidation by bacteroids: effect of $\mathrm{NaCl}$}

In agreement with previous results (Fougère \& Le Rudulier, 1990), the rate of $\left[{ }^{14} \mathrm{C}\right]$ choline uptake was almost constant during the whole experiment and was stimulated twofold by increasing the osmolarity of the incubation medium: after a $3 \mathrm{~h}$ incubation, 8 and $17 \%$ of the initial radioactivity was taken up by the bacteroids incubated in low- and high-salt medium, respectively (results not shown). 


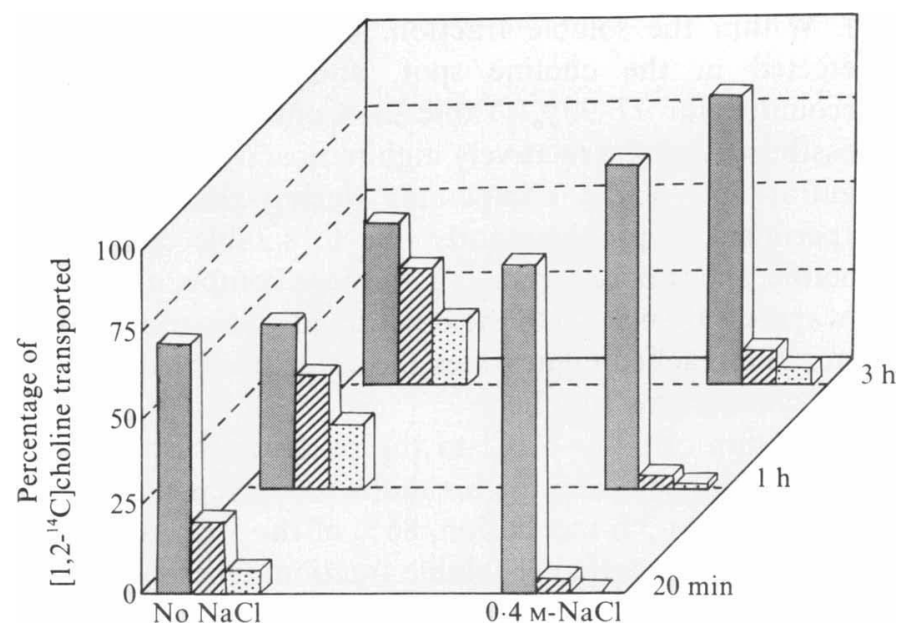

Fig. 1. Effect of $\mathrm{NaCl}$ on $\left[1,2-{ }^{14} \mathrm{C}\right]$ choline catabolism by bacteroids of R. meliloti. Incubation mixtures $(1 \mathrm{ml})$ contained $8 \mu \mathrm{M}-\left[1,2-{ }^{14} \mathrm{C}\right]$ choline and $0.9 \mathrm{mg}$ bacteroid protein in $25 \mathrm{~mm}$-potassium phosphate buffer ( $\mathrm{pH} 7.4$ ) with 0 or $0.4 \mathrm{M}-\mathrm{NaCl}$. At the indicated time, the cells were filtered and treated as described in Methods. Distribution of ${ }^{14} \mathrm{C}$ among the ethanol-soluble fraction (representing choline and its metabolites; $\square$ ), the ethanol-insoluble fraction (corresponding to cellular material; $\square$ ), and $\mathrm{CO}_{2}$ released ( $\because$ ) was expressed as a percentage of the $\left[{ }^{14} \mathrm{C}\right]$ choline taken up by the bacteroids.

$\left[1,2-{ }^{14} \mathrm{C}\right]$ Choline was actively catabolized by isolated bacteroids resuspended in medium of low osmolarity (Fig. 1). After 20 min of incubation, 72, 21 and $7 \%$ of the ${ }^{14} \mathrm{C}$ taken up was found in ethanol-soluble, ethanolinsoluble and $\mathrm{CO}_{2}$ fractions, respectively. After $1 \mathrm{~h}$, the percentage of radioactivity tripled in $\mathrm{CO}_{2}$, strongly increased in the insoluble fraction $(57 \%)$, and was significantly reduced in the soluble fraction $(33 \%)$.
During the last $2 \mathrm{~h}$ of incubation, the percentages of radioactivity in all fractions remained unchanged. The ethanol-soluble fraction was analysed (Table 1). After $20 \mathrm{~min}$ incubation, $74 \%$ of the soluble fraction was recovered as choline itself but only 28 and $8 \%$ remained after 1 and $3 \mathrm{~h}$, respectively. Thus, free choline rapidly disappeared, and less than $4 \%$ of the amount taken up was left at the end. Glycine betaine was the predominant labelled compound after $1 \mathrm{~h}$ but the proportion of radioactivity in this compound later decreased significantly. In addition, during the last $2 \mathrm{~h}$ of incubation, substantial radioactivity was also found in neutral and acidic compounds which might represent soluble esters of $\left[{ }^{14} \mathrm{C}\right]$ choline, including phosphorylcholine, carbohydrates, and oligopeptides or large cellular components.

The effect of salt stress on choline catabolism was tested by adding $\mathrm{NaCl}(0.4 \mathrm{M}$ final concentration) to the bacteroid suspension. The distribution of ${ }^{14} \mathrm{C}$ between ethanol-soluble, ethanol-insoluble and $\mathrm{CO}_{2}$ fractions changed slightly during the experiment (Fig. 1): after a $3 \mathrm{~h}$ incubation only 10 and $5 \%$ of the radioactivity was detected into the last two fractions. Within the soluble fraction, approximately $90 \%$ of the ${ }^{14} \mathrm{C}$ was always recovered as glycine betaine. Intracellular choline was totally catabolized and less than $5 \%$ of the labelling represented neutral and acidic compounds, even after $3 \mathrm{~h}$ (Table 1). Addition of $\mathrm{NaCl}$ did not significantly influence the percentage of radioactivity in sarcosine and glycine.

During an additional $3 \mathrm{~h}$ experiment with [methyl$\left.{ }^{14} \mathrm{C}\right]$ choline, production of $\left[{ }^{14} \mathrm{C}\right]$ trimethylamine could not be demonstrated, whatever the osmolarity of the incubation medium.

Table 1. Effect of $\mathrm{NaCl}$ on the distribution of ${ }^{14} \mathrm{C}$ within the ethanol-soluble fraction of bacteroids of $R$. meliloti supplied with $\left[1,2-{ }^{14} C\right]$ choline

Bacteroids were incubated with $\left[1,2-{ }^{14} \mathrm{C}\right]$ choline as described in Fig. 1 and extracted at the indicated time. Ethanol-soluble compounds were identified as mentioned in Methods. Results are expressed as a percentage of the total label of the ethanol-soluble extract.

\begin{tabular}{|c|c|c|c|c|c|c|}
\hline \multirow{3}{*}{$\begin{array}{l}{ }^{14} \mathrm{C} \text {-labelled } \\
\text { compound } \\
\text { recovered }\end{array}$} & \multicolumn{6}{|c|}{ Incubation mixture: } \\
\hline & \multicolumn{3}{|c|}{ No salt } & \multicolumn{3}{|c|}{$0.4 \mathrm{M}-\mathrm{NaCl}$} \\
\hline & $20 \mathrm{~min}$ & $1 \mathrm{~h}$ & $3 \mathrm{~h}$ & $20 \mathrm{~min}$ & $1 \mathrm{~h}$ & $3 \mathrm{~h}$ \\
\hline Choline & $74 \cdot 2$ & 27.9 & $8 \cdot 4$ & $3 \cdot 7$ & $3 \cdot 2$ & $1 \cdot 0$ \\
\hline Glycine betaine & $23 \cdot 1$ & $42 \cdot 5$ & $16 \cdot 7$ & $94 \cdot 0$ & 89.9 & 91.6 \\
\hline Sarcosine & 0 & 0 & 0.7 & 0.7 & $0 \cdot 5$ & 1.7 \\
\hline Glycine & $0 \cdot 7$ & $1 \cdot 6$ & $2 \cdot 0$ & 0.7 & 0.9 & 0.9 \\
\hline 'Neutral' compounds* & $0 \cdot 8$ & $24 \cdot 7$ & $37 \cdot 0$ & 0 & $3 \cdot 0$ & $3 \cdot 1$ \\
\hline 'Acidic' compounds* & 0 & $1 \cdot 6$ & $34 \cdot 0$ & 0 & 0.5 & 1.4 \\
\hline
\end{tabular}

* These compounds remained at the origin (neutral) or slightly migrated toward the anode (acidic) during electrophoresis of the extract. 


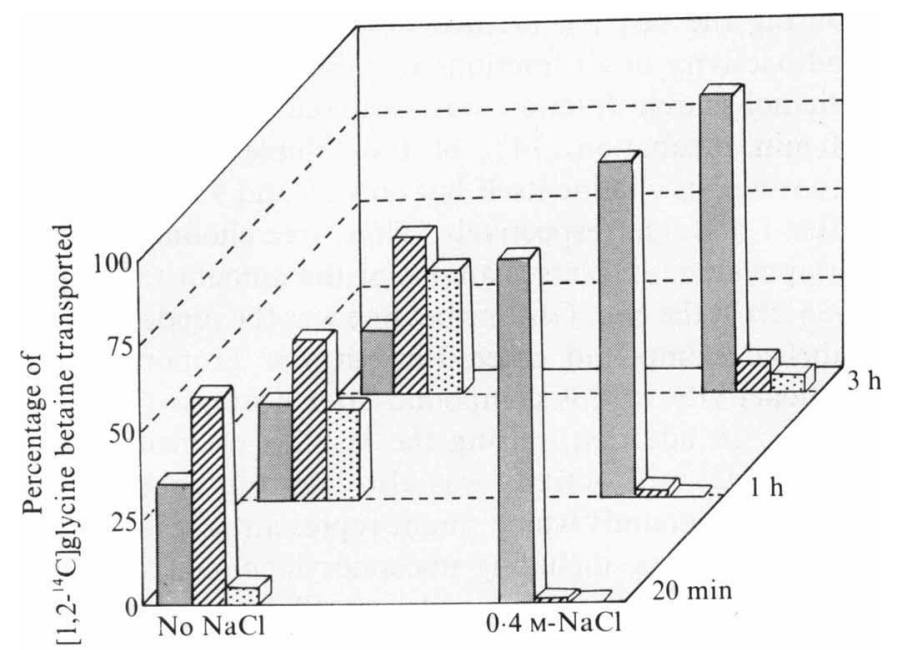

Fig. 2. Effect of $\mathrm{NaCl}$ on $\left[1,2-{ }^{14} \mathrm{C}\right]$ glycine betaine catabolism by bacteroids of $R$. meliloti. Incubation mixtures $(1 \mathrm{ml})$ contained $9 \mu \mathrm{M}-$ $\left[1,2-{ }^{14} \mathrm{C}\right]$ glycine betaine and $0.7 \mathrm{mg}$ bacteroid protein in $25 \mathrm{~mm}-$ potassium phosphate buffer ( $\mathrm{pH} 7 \cdot 4)$ with 0 or $0.4 \mathrm{M}-\mathrm{NaCl}$. Experimental conditions were as described in Fig. 1. 圆, Ethanol-soluble fraction; $\square$, ethanol-insoluble fraction; $\mathrm{B}, \mathrm{CO}_{2}$.

Effect of salt stress on glycine betaine catabolism by bacteroids

Because the uptake of $\left[{ }^{14} \mathrm{C}\right] \mathrm{glycine}$ betaine was strongly stimulated by $\mathrm{NaCl}$ (Fougère \& Le Rudulier, 1990), 7 and $56 \%$ of the supplied ${ }^{14} \mathrm{C}$-labelled substrate had been removed, at the end of the experiment, from the low- and high-salt medium, respectively.

In the low-salt medium, $[1,2-14 \mathrm{C}] \mathrm{glycine}$ betaine was rapidly catabolized: only $19 \%$ of the ${ }^{14} \mathrm{C}$ taken up remained in the ethanol-soluble fraction after $3 \mathrm{~h}$ incubation whereas 45 and $36 \%$ was found in the ethanol-insoluble and $\mathrm{CO}_{2}$ fractions, respectively (Fig.
2). Within the soluble fraction, no radioactivity was detected in the choline spot, and glycine betaine accounted for $77-90 \%$ (Table 2). Consistent with the possibility that the relatively high radioactivity found in neutral and acidic compounds during the previous experiment is predominantly due to soluble esters of choline, the proportion of ${ }^{14} \mathrm{C}$ in these compounds was always less than $9 \%$. On the other hand, radioactivity in sarcosine reached eight times the value observed when $\left[{ }^{14} \mathrm{C}\right]$ choline was supplied.

Addition of $0.4 \mathrm{M}-\mathrm{NaCl}$ to the bacteroid suspension almost totally blocked the breakdown of glycine betaine (Fig. 2). After $3 \mathrm{~h}$ incubation, $86 \%$ of the ${ }^{14} \mathrm{C}$ taken up remained in the ethanol-soluble fraction, where glycine betaine itself never represented less than $96 \%$ (Table 2).

As with $\left[\right.$ methyl $\left.{ }^{14} \mathrm{C}\right]$ choline, metabolism of [methyl$\left.{ }^{14} \mathrm{C}\right]$ glycine betaine never produced $\left[{ }^{14} \mathrm{C}\right]$ trimethylamine.

Evidence for choline oxidase and glycine betaine aldehyde dehydrogenase in bacteroids

Because the bacteroids converted a large amount of [1,2${ }^{14} \mathrm{C}$ ]choline to glycine betaine, we focused on enzymic activities already characterized in free-living $R$. meliloti : choline oxidase and glycine betaine aldehyde dehydrogenase (Smith et al., 1988).

The oxidation of $\left[\right.$ methyl $\left.{ }^{-14} \mathrm{C}\right]$ choline to glycine betaine aldehyde was catalysed by toluene-treated bacteroids. The choline oxidase activity displayed Michaelis-Menten kinetics. The apparent $K_{\mathrm{m}}$ value for choline was $2 \cdot 0 \pm 0 \cdot 2 \mathrm{~mm}$ (mean of duplicates from two separate experiments, $\pm \mathrm{SD}$ ) and the maximal velocity

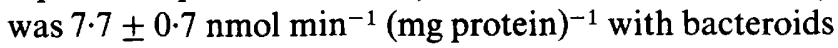
suspended in $100 \mathrm{mM}$-potassium phosphate buffer, pH 7.6. As previously observed with $E$. coli and $R$.

Table 2. Effect of $\mathrm{NaCl}$ on the distribution of ${ }^{14} \mathrm{C}$ within the ethanol-soluble fraction of bacteroids of $R$. meliloti supplied with $[1,2-14 C]$ glycine betaine

Bacteroids were incubated with $\left[1,2-{ }^{14} \mathrm{C}\right]$ glycine betaine as described in Fig. 2 and extracted at the indicated time. Results are expressed as a percentage of the total label of the ethanol-soluble extract.

\begin{tabular}{|c|c|c|c|c|c|c|}
\hline \multirow{3}{*}{$\begin{array}{l}{ }^{14} \mathrm{C} \text {-labelled } \\
\text { compound } \\
\text { recovered }\end{array}$} & \multicolumn{6}{|c|}{ Incubation mixture: } \\
\hline & \multicolumn{3}{|c|}{ No salt } & \multicolumn{3}{|c|}{$0.4 \mathrm{M}-\mathrm{NaCl}$} \\
\hline & $20 \mathrm{~min}$ & $1 \mathrm{~h}$ & $3 \mathrm{~h}$ & $20 \mathrm{~min}$ & $1 \mathrm{~h}$ & $3 \mathrm{~h}$ \\
\hline Glycine betaine & 89.9 & $77 \cdot 0$ & $78 \cdot 4$ & $96 \cdot 6$ & $98 \cdot 7$ & $98 \cdot 3$ \\
\hline Sarcosine & $3 \cdot 2$ & $3 \cdot 1$ & $6 \cdot 1$ & 1.5 & 0.7 & $0 \cdot 6$ \\
\hline Glycine & $2 \cdot 0$ & 4.6 & $2 \cdot 8$ & $0 \cdot 2$ & 0.3 & 0.6 \\
\hline 'Neutral' compounds* & $2 \cdot 7$ & 6.2 & $8 \cdot 4$ & 0 & 0.1 & $0 \cdot 3$ \\
\hline “Acidic' compounds* & 0.5 & $9 \cdot 1$ & $2 \cdot 6$ & 1.7 & $0 \cdot 1$ & $0 \cdot 1$ \\
\hline
\end{tabular}

* As in Table 1. 


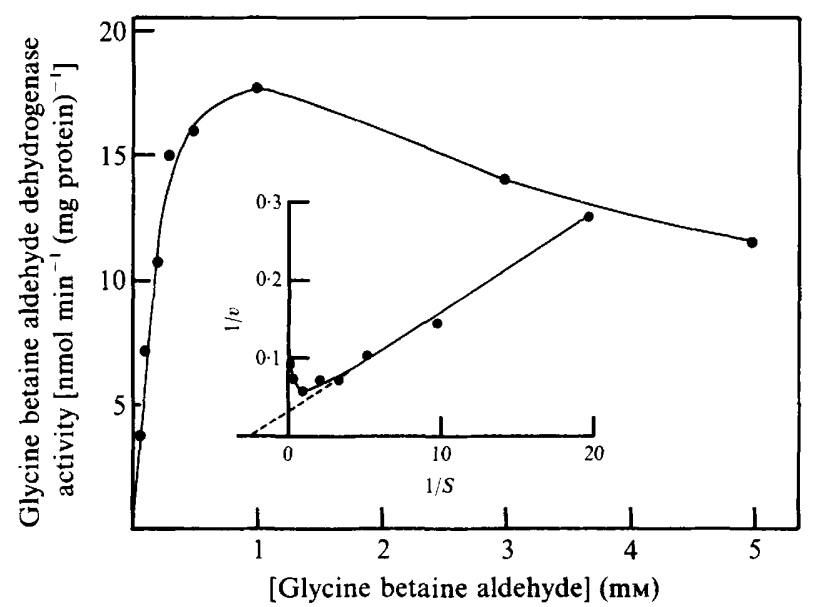

Fig. 3. Kinetics of glycine betaine aldehyde dehydrogenase from bacteroids of $R$. meliloti. Incubation mixtures $(1 \mathrm{ml})$ contained $0.4 \mathrm{mg}$ bacteroid protein, $0.05-5 \mathrm{~mm}$-glycine betaine aldehyde, $10 \mathrm{mM}-\mathrm{NAD}^{+}$ and $100 \mathrm{~mm}$-potassium phosphate ( $\mathrm{pH} \mathrm{7.6)}$. The insert is the double reciprocal plot of glycine betaine aldehyde dehydrogenase activity, $v$, against substrate concentration, $S$.

meliloti (Landfald \& Strøm, 1986; Smith et al., 1988), it should be noted that bacteroids made permeable to choline by toluene treatment retained higher specific enzyme activity than crude extracts of bacteroids disrupted in a French pressure cell.

Bacteroid lysates also readily oxidized glycine betaine aldehyde; maximal enzyme activity, $17.7 \pm 2.5 \mathrm{nmol}$ $\min ^{-1}$ (mg protein) ${ }^{-1}$ occurred with 1 mM-glycine betaine aldehyde. Unexpectedly, this activity was slightly inhibited by $5 \mathrm{mM}$-substrate (Fig. 3). The apparent $K_{\mathrm{m}}$ was $0.4 \pm 0.1 \mathrm{mM}$ and the calculated maximal rate was $33 \pm 3 \mathrm{nmol} \mathrm{min}{ }^{-1}$ (mg protein $)^{-1}$. These relatively high affinity and maximal velocity values help to prevent intracellular accumulation of glycine betaine aldehyde.

\section{Effect of $\mathrm{NaCl}$ on enzyme activities involved in glycine betaine biosynthesis}

Because the biosynthetic pathway of glycine betaine has been shown to be modulated by the external osmotic pressure and the presence of choline (Landfald \& Strøm, 1986; Smith et al., 1988), we examined choline oxidase and glycine betaine aldehyde dehydrogenase activities in isolated bacteroids preincubated for $3 \mathrm{~h}$ in $25 \mathrm{~mm}$ potassium phosphate buffer supplemented or not with $0.4 \mathrm{M}-\mathrm{NaCl}$, and with or without $10 \mathrm{~mm}$-choline.

In the absence of choline, bacteroids incubated in buffer with $0.4 \mathrm{M}-\mathrm{NaCl}$ showed a $59 \%$ increase in choline oxidase activity, whereas only an $11 \%$ increase was observed in the glycine betaine aldehyde dehydrogenase activity (Table 3 ). The addition of choline had essentially no effect on either enzymic activity when bacteroids were resuspended in low-osmolarity buffer, nor on the glycine betaine aldehyde dehydrogenase activity of bacteroids maintained in high-osmolarity buffer. However, the presence of choline in $0.4 \mathrm{M}-\mathrm{NaCl}$ medium slightly $(18 \%)$ decreased the choline oxidase activity. Obviously, such a short preincubation time $(3 \mathrm{~h})$ did not allow the induction of the enzymes. In the absence of $\mathrm{NaCl}$ and choline, both enzyme activities were slightly lower in preincubated bacteroids than in bacteroids used immediately after isolation: 22 and $26 \%$ decreases were observed for choline oxidase and glycine betaine aldehyde dehydrogenase, respectively.

To study the effect of a longer salt stress period, enzyme activities were investigated in bacteroids isolated from $M$. sativa plants subjected to salt stress $(0 \cdot 15 \mathrm{M}-\mathrm{NaCl})$ for 2 weeks. The choline oxidase activity of such bacteroids was only slightly $(17 \%)$ enhanced $\left[8 \cdot 2 \pm 0 \cdot 4\right.$ versus $\left.7 \cdot 0 \pm 0 \cdot 3 \mathrm{nmol} \mathrm{min}^{-1}(\mathrm{mg} \text { protein })^{-1}\right]$, while the glycine betaine aldehyde dehydrogenase

Table 3. Effect of $\mathrm{NaCl}$ on choline oxidase and glycine betaine aldehyde dehydrogenase activities in bacteroids of $R$. meliloti

Bacteroids (3-4 mg protein) were preincubated aerobically at $25^{\circ} \mathrm{C}$ for $3 \mathrm{~h}$ in $2 \mathrm{ml}$ $25 \mathrm{~mm}$-potassium phosphate buffer (pH 7.4) with 0 or $0.4 \mathrm{M}-\mathrm{NaCl}$, and 0 or $10 \mathrm{~mm}$ choline. Bacteroids were then centrifuged at $7000 \mathrm{~g}$ for $10 \mathrm{~min}$, and resuspended in 100 mM-potassium phosphate buffer ( $\mathrm{pH} 7 \cdot 6$ ). They were permeabilized with toluene for choline oxidase measurements or disrupted by passages through a French press for glycine betaine aldehyde dehydrogenase determinations. Enzyme activities were determined as described in Methods. Values are the mean of duplicate determinations from two separate experiments, \pm SD.

\begin{tabular}{|c|c|c|c|}
\hline \multicolumn{2}{|c|}{ Preincubation medium } & \multirow{2}{*}{$\begin{array}{c}\text { Choline oxidase } \\
{\left[\mathrm{nmol} \mathrm{min}^{-1}(\mathrm{mg} \text { protein })^{-1}\right]}\end{array}$} & \multirow{2}{*}{$\begin{array}{c}\text { Glycine betaine aldehyde } \\
\text { dehydrogenase } \\
\text { [nmol } \min ^{-1}(\text { mg protein })^{-1} \text { ] }\end{array}$} \\
\hline $\mathrm{NaCl}$ & Choline & & \\
\hline None & 0 & $4 \cdot 4 \pm 0 \cdot 2$ & $13 \cdot 1 \pm 2 \cdot 0$ \\
\hline None & $10 \mathrm{~mm}$ & $4.9 \pm 0.3$ & $13.9 \pm 0.4$ \\
\hline $0.4 \mathrm{M}$ & 0 & $7 \cdot 0 \pm 0.2$ & $14.5 \pm 1.4$ \\
\hline $0.4 \mathrm{M}$ & $10 \mathrm{~mm}$ & $5.8 \pm 0.1$ & $15 \cdot 3 \pm 0.5$ \\
\hline
\end{tabular}


activity remained almost unchanged $[10 \%$ decrease: $15.8 \pm 0.4$ versus $17.6 \pm 1.1 \mathrm{nmol} \mathrm{min}^{-1}(\mathrm{mg} \text { protein })^{-1}$ (means of duplicates from two separate experiments $\pm \mathrm{SD})]$. Thus, it seems unlikely that salt stress has a determinative influence on the two enzymes involved in glycine betaine biosynthesis in bacteroids of $R$. meliloti.

\section{Discussion}

Our data establish that bacteroids isolated from alfalfa nodules actively catabolize $\left[{ }^{14} \mathrm{C}\right]$ choline. Radiotracer experiments showed that the labelling patterns were strongly influenced by the salt concentration of the incubation medium, insofar as ${ }^{14} \mathrm{C}$ accumulated with time in the ethanol-insoluble and $\mathrm{CO}_{2}$ fractions in bacteroids suspended at low osmolarity, whereas the ${ }^{14} \mathrm{C}$ remained in the ethanol-soluble fraction in salt-stressed bacteroids. Furthermore, the salt treatment significantly modified the distribution of the radioactivity within the soluble fraction: at high osmolarity $90 \%$ of the label entered glycine betaine, but at low osmolarity $70 \%$ of the label incorporation was into neutral compounds, including phosphorylcholine, and acidic compounds. The increased conversion of $\left[{ }^{14} \mathrm{C}\right]$ choline to glycine betaine in salt-stressed bacteroids provides direct evidence for a more efficient synthesis of the betaine in bacteroids subjected to high osmolarity. Similar results have been obtained with free-living $R$. meliloti (Smith et al., 1988) but, interestingly, also in different plants. For example, when $\left[{ }^{14} \mathrm{C}\right]$ choline was supplied to barley or spinach leaves, the major labelled aqueous products were glycine betaine and phosphorylcholine. The kinetics of ${ }^{14} \mathrm{C}$ incorporation into both compounds showed that wilting markedly increased the entry of ${ }^{14} \mathrm{C}$ into glycine betaine in barley leaves (Hanson \& Scott, 1980; Hitz et al., 1981), whereas salinization of the plants had no significant effect in spinach leaves (Coughlan \& Wyn Jones, 1982).

It must be emphasized that choline, the precursor of glycine betaine, is universally present in plants, and several forms of choline within the host cells could become available for glycine betaine production. Such pools include free choline, water-soluble bound forms of choline such as phosphorylcholine and glycerylphosphorylcholine, and lipid choline as phosphatidylcholine. $M$. sativa is known to contain choline in its shoots (Wyn Jones \& Storey, 1981), but also in suspension tissue cultures, where the highest amount of choline appears in tissue of root origin (Sethi \& Carew, 1974). In addition, it has been shown that alfalfa shoots accumulated choline when osmotically stressed by $0 \cdot 1 \mathrm{M}-\mathrm{NaCl}$ (Wyn Jones \& Storey, 1981); similarly, in leaf blades of barley plants, free choline levels increased rather than fell during water stress (Hanson \& Nelsen, 1978). Phosphorylcholine is also known as an important constituent of plant saps (Maizel et al., 1956), and phosphatidylcholine, the major plant phospholipid (Kates \& Marshall, 1975), is actively synthesized by alfalfa leaflet tissue supplied with [1,2${ }^{14} \mathrm{C}$ ]choline (Willemot \& Verret, 1973). Since the phosphatidylcholine and the phosphorylcholine could be hydrolysed by phospholipase $\mathrm{D}$, the released choline might be available for oxidation to glycine betaine in bacteroids. The potential for a lipid-dependent pathway of glycine betaine biosynthesis also exists in spinach (Hanson \& Scott, 1980). In nodules subjected to salt stress, minor modifications of the membrane integrity would, in turn, result in an increase of endogenous choline pools. In fact, it has been shown recently that water stress modified the structure of Vicia faba nodules, and it was suggested that proteases were responsible for protein digestion within the host cell (Guérin et al., 1990). Thus, it is tempting to speculate that alterations of membranes during osmotic stress account for a significant proportion of the rate of glycine betaine biosynthesis. A bacteroid site for choline oxidation is certainly interesting from the viewpoint of the proposal which accords glycine betaine synthesis a major role in adaptation to osmotic stress, and also in preservation of nitrogenase activity in nitrogen-fixing organisms subjected to salt stress (Le Rudulier \& Bouillard, 1983; Pocard et al., 1984).

Enzymic studies indicate that a membrane-bound choline oxidase and a soluble glycine betaine aldehyde dehydrogenase are both present in alfalfa bacteroids as previously observed in free-living $R$. meliloti (Smith et al., 1988). Comparison of enzymic activities in control and salt-stressed bacteroids suggested that the enhanced rate of choline conversion to glycine betaine in the presence of $\mathrm{NaCl}$ may not result from an increase in both enzyme activities. The choline oxidase and the glycine betaine aldehyde dehydrogenase activities were almost the same in unstressed bacteroids and in bacteroids that had been salt stressed for $3 \mathrm{~h}$. A long-term salt stress of the host plants did not promote either of the enzyme activities of the bacteroids. A different situation was observed in spinach chloroplasts, where the activity of glycine betaine aldehyde dehydrogenase is regulated by salt stress, and increased threefold in response to gradual salinization of spinach plants (Weigel et al., 1986). Such salinization greatly increased the abundance of translatable glycine betaine aldehyde dehydrogenase mRNA, raising the possibility that salt stress activates the transcription of the glycine betaine aldehyde dehydrogenase gene (Weretilnyk \& Hanson, 1989).

The presence of choline in the bacteroid incubation medium during $3 \mathrm{~h}$ incubation was also without significant effect on enzymes activities of the choline-glycine 
betaine pathway. In $R$. meliloti, these activities are greatly stimulated when choline is present in the medium (Smith et al., 1988). However, in free-living cells both enzymes reached a maximal specific activity after $24 \mathrm{~h}$ of culture and only a minor increase was observed after $5 \mathrm{~h}$. Thus, $3 \mathrm{~h}$ incubation of the bacteroids in the presence of choline might not be long enough to stimulate both enzymes. This contention is supported by previous results obtained with nitrate reductase of Phaseolus vulgaris bacteroids, where enzyme induction needs at least $9 \mathrm{~h}$ incubation in the presence of nitrate (Rigaud, 1976).

Our results also revealed that glycine betaine was actively catabolized by unstressed bacteroids while the catabolic system was blocked by increasing the salt concentration of the incubation medium. In this way, a substantial amount of glycine betaine can be maintained in stressed bacteroids. Similar results have been obtained with free-living R. meliloti (Bernard et al., 1986), whereas in plants, once synthesized, glycine betaine is usually not detectably catabolized and behaves as an inert endproduct during or upon relief of stress (Ahmad \& Wyn Jones, 1979; Ladyman et al., 1980; Hanson \& Wyse, 1982). Since proline betaine is also synthesized by $M$. sativa (Sethi \& Carew, 1974) and actively taken up by alfalfa bacteroids (Fougère \& Le Rudulier, 1990), the question of the role of this betaine in bacteroids is being addressed.

This research was supported by the Centre National de la Recherche Scientifique. We wish to thank Marie-Christine Poggi for excellent technical assistance, and Hélène Le Bris and Martine Sigwald for assistance in typing the manuscript.

\section{References}

Ahmad, N. \& Wyn Jones, R. G. (1979). Comparative turnover of glycine betaine and proline in barley plants released from salt and osmotic stress. Plant Science Letters 15, 231-237.

Bernard, T., Pocard, J. A., Perroud, B. \& Le Rudulier, D. (1986). Variations in the response of salt-stressed Rhizobium strains to betaines. Archives of Microbiology 143, 359-364.

Bowman, M. S. \& Rohringer, R. (1970). Formate metabolism in healthy and rust-infected wheat. Canadian Journal of Botany 48 , 803-811.

COUGHLAN, S. J. \& WYN JONES, R. G. (1982). Glycine betaine biosynthesis and its control in detached secondary leaves of spinach. Planta 154, 6-17.

FOUGÈRE, F. \& LE RUDULIER, D. (1990). Uptake of glycine betaine and its analogues by bacteroids of Rhizobium meliloti. Journal of General Microbiology 136, 157-163.

Grumet, R. \& Hanson, A. D. (1986). Genetic evidence for an osmoregulatory role of glycine betaine accumulation in barley. Australian Journal of Plant Physiology 13, 353-364.

Guérin, V., Trinchant, J. C. \& Rigaud, J. (1990). Nitrogen fixation $\left(\mathrm{C}_{2} \mathrm{H}_{2}\right.$ reduction) by broad bean (Vicia faba L.) nodules and bacteroids under water restricted conditions. Plant Physiology 92, 595-601.

HANSON, A. D. \& Hitz, W. D. (1982). Metabolic responses of mesophytes to plant water deficits. Annual Review of Plant Physiology 33, 163-203.
Hanson, A. D. \& Nelsen, C. E. (1978). Betaine accumulation and $\left[{ }^{14} \mathrm{C}\right]$ formate metabolism in water-stressed barley leaves. Plant Physiology 62, 305-312.

HANSON, A. D. \& RHODEs, D. (1983). ${ }^{14} \mathrm{C}$ tracer evidence for synthesis of choline and betaine via phosphoryl base intermediates in salinized sugarbeet leaves. Plant Physiology 71, 692-700.

Hanson, A. D. \& Scotr, N. A. (1980). Betaine synthesis from radioactive precursors in attached, water-stressed barley leaves. Plant Physiology 66, 342-348.

HANSON, A. D. \& WYSE, R. (1982). Biosynthesis, translocation, and accumulation of betaine in sugar beet and its progenitors in relation to salinity. Plant Physiology 70, 1191-1198.

Hanson, A. D., May, A. M., Grumet, R., Bode, J., Jamieson, G. C. \& RHODES, D. (1985). Betaine synthesis in chenopods: localization in chloroplasts. Proceedings of the National Academy of Sciences of the United States of America 82, 3678-3682.

Hitz, W. D., Rhodes, D. \& Hanson, A. D. (1981). Radiotracer evidence implicating phosphoryl and phosphatidyl bases as intermediate in betaine synthesis by water-stressed barley leaves. Plant Physiology 68, 814-822.

KaTES, M. \& Marshall, M. O. (1975). Biosynthesis of phosphoglycerides in plants. In Recent Advances in the Chemistry and Biochemistry of Lipids, pp. 115-159. Edited by T. Galliard \& E. I. Mercer. London: Academic Press.

Ladyman, J. A. R., Hitz, W. D. \& Hanson, A. D. (1980). Translocation and metabolism of glycine betaine by barley plants in relation to water stress. Planta 150, 191-196.

LandFald, B. \& STRøM, A. R. (1986). Choline-glycine betaine pathway confers a high level of osmotic tolerance in Escherichia coli. Journal of Bacteriology 165, 849-855.

LE Rudulier, D. \& BouillaRd, L. (1983). Glycine betaine, an osmotic effector in Klebsiella pneumoniae and other members of the Enterobacteriaceae. Applied and Environmental Microbiology 46, 152-159.

Le Rudulier, D., YANG, S. S. \& Csonka, L. N. (1982). Nitrogen fixation in Klebsiella pneumoniae during osmotic stress. Effect of exogenous proline or a proline overproducing plasmid. Biochimica et Biophysica Acta 719, 273-283.

Le Rudulier, D., Strøm, A. R., Dandekar, A. M., Smith, L. T. \& VALENTINE, R. C. (1984). Molecular biology of osmoregulation. Science 224, 1064-1068.

MacDonnell, E. \& WYN Jones, R. G. (1988). Glycine betaine biosynthesis and accumulation in unstressed and salt-stressed wheat. Journal of Experimental Botany 39, 421-430.

Maizel, J. V., Benson, A. A. \& TolberT, N. E. (1956). Identification of phosphorylcholine as an important constituent of plant saps. Plant Physiology 31, 407-408.

Perroud, B. \& Le Rudulier, D. (1985). Glycine betaine transport in Escherichia coli: osmotic modulation. Journal of Bacteriology 161, 393-401.

Pocard, J. A., Bernard, T., Goas, G. \& Le Rudulier, D. (1984). Restauration partielle, par la glycine bétaïne et la proline bétaîne, de l'activité fixatrice d'azote de jeunes plantes de Medicago sativa $L$. soumises à un stress hydrique. Comptes-Rendus de l'Académie des Sciences 298, 477-480.

Rigaud, J. (1976). Effet des nitrates sur la fixation d'azote par les nodules de Haricot (Phaseolus vulgaris L.). Physiologie Végétale 14, 297-308.

SETHI, J. K. \& CAREW, D. P. (1974). Growth and betaine formation in Medicago sativa tissue cultures. Phytochemistry 13, 321-324.

Smith, L. T., Pocard, J. A., Bernard, T. \& Le Rudulier, D. (1988). Osmotic control of glycine betaine biosynthesis and degradation in Rhizobium meliloti. Journal of Bacteriology 170, 3142-3149.

Weigel, P., Weretilnyk, E. A. \& Hanson, A. D. (1986). Betaine aldehyde oxidation by spinach chloroplasts. Plant Physiology 82, 753-759.

Weigel, P., Lerma, C. \& Hanson, A. D. (1988). Choline oxidation by intact spinach chloroplasts. Plant Physiology 86, 54-60.

WeretilnYK, E. A. \& Hanson, A. D. (1989). Betaine aldehyde dehydrogenase from spinach leaves: purification, in vitro translation of the mRNA, and regulation by salinity. Archives of Biochemistry and Biophysics 271, 56-63. 
Willemot, C. \& VerRet, G. (1973). Incorporation of choline-1,2-14C into molecular species of phosphatidylcholine by alfalfa leaflet tissue. Lipids 8, 588-591.
WyN Jones, R. G. \& Storey, R. (1981). Betaines. In Physiology and Biochemistry of Drought Resistance in Plants, pp. 171-204. Edited by L. G. Paleg \& D. Aspinall. Sydney: Academic Press. 